\title{
BusCa POR REPRESENTAÇÃO: A PSICANÁLISE E O TRABALHO DE CONSTRUÇÁO
}

\author{
SEARCHING FOR REPRESENTATION: PSYCHOANALYSIS \\ AND THE CONSTRUCTION PROCESS \\ BÚSQUEDA POR REPRESENTACIÓN PSÍQUICA: \\ PSICOANÁLISIS Y EL TRABAJO DE CONSTRUCCIÓN
}

Simone Bianchi Sanches*

\section{Resumo}

O objetivo desse trabalho é apresentar as modificaçōes técnicas decorrentes de avanços na teoria psicanalítica a partir do conceito de campo analítico e das contribuiçóes de Bion, especialmente do impacto provocado pela consideração da identificação projetiva como comunicaçáo. Destaca-se a importância da construção de representaçôes daquilo que permanece como força "bruta" no psiquismo, em geral aspectos primitivos e pré-verbais, portanto sensoriais. Tais consideraçóes têm sido acompanhadas de progressiva valorizaçáo da acuidade intuitiva do analista e seu instrumento de captação de emoçôes, especialmente frente aos estados mais primitivos da mente.

Palavras-chave: psicanálise; construção; representação; não representação.

\section{Abstract}

The objective of this paper is to present the technical modifications resulted from psychoanalytic theory advances departing from analytical field concept and Bion's contributions, particularly the impact caused by the consideration of projective identification as a communication. We point out the importance of the representation construction of what remains as brutal strength in the psyche, which in general are primitive or pre-verbal aspects; therefore, sensory. Such considerations have been followed by progressive valorization of the analyst's intuiti-

* Universidade de São Paulo, Ribeirão Preto, SP, Brasil. 
ve acuteness and his/her emotion captivation instrument, particularly related to the most primitive states of the mind.

Keywords:psychoanalysis; construction; representation;non-representation.

\section{RESUMEN}

El objetivo de este trabajo es presentar los cambios técnicos derivados del desarrollo en la teoría psicoanalítica, a partir del concepto del campo analítico y las contribuciones de Bion, especialmente el impacto causado por la consideración de la identificación proyectiva como herramienta de comunicación. Resaltamos la importancia de la construcción de representaciones de lo que permanece como fuerza "bruta" en la psique, en general los aspectos primitivos y pre-verbales, por lo tanto, sensoriales. Estas consideraciones han sido acompañadas por la apreciación de la agudeza intuitiva del analista y sus recursos para percepción de emociones, sobre todo de los estados más primitivos de la mente.

Palabras clave: psicoanálisis; construcción; representación; falta de representación.

Se nas descriçōes da técnica analítica se fala tão pouco sobre "construçóes", isso se deve ao fato de que, em troca, se fala nas "interpretaçôes" e em seus efeitos. Mas acho que "construção"é, de longe, a descrição mais apropriada. Freud, 1937, "Construções em análise"

\section{Modelos teóricos e implicaçóes técnicas - passado e presente}

Os avanços teóricos da psicanálise favoreceram modificações na abordagem clínica, ampliando as possibilidades de trabalho com a técnica, além da interpretação.

Diversos autores (Alvarez, 1994; Ferro, 1995) têm descrito a relação existente entre os modelos teóricos clássicos e as consequentes modificaçôes na teoria da técnica e na própria maneira como a psicanálise se realiza (Alvarez, 1994).

Assim, no modelo psicanalítico clássico, a construção em psicanálise fazia referência à retomada de fragmentos cristalizados, memórias e experiências passadas que pudessem ser relembradas e ressignificadas. Atualmente, contudo, a construção refere-se também a um inconsciente permanentemente sendo constituído, inacabado e dinâmico, conforme nos sugerem os avanços da psicanálise e a teoria do pensamento de Bion. 
Essa "arquitetura" combina muito com os progressos de uma psicanálise rica e criativa, mas ainda capaz de encontrar lugar de destaque para os "vestígios remanescentes" (Freud, 1937/1980), que darão o tom da construção. Ou seja, o desafio existe justamente porque o suporte para a criação de algo inovador apoia-se, na verdade, nos aspectos estruturais da personalidade do paciente, que permanecem como guias no projeto de construção.

Sob esse ponto de vista, é inegável que o modelo arqueológico foi sendo modificado por expansões na compreensão do funcionamento mental e inclusão dinâmica do analista. Assim, se por um lado os progressos da psicanálise nos libertam das ferramentas de escavação, por outro nos convocam a participar de um projeto ainda desconhecido, em cujo alicerce também estarão os recursos da nossa mente.

Nesse sentido, os conceitos de intersubjetividade, relação bipessoal e campo analítico (Baranger, citado por Ferro, 1995) passaram a nortear a psicanálise contemporânea, em que a relação analista - paciente permite a "construção de algo psíquico criado pela primeira vez" (Falcão, 2008, p. 69), inexistente até então.

Essas consideraçóes alteram fortemente a maneira como passado e presente se articulam na aproximaçáo do paciente e no próprio objetivo da psicanálise, com uma ênfase cada vez maior na experiência emocional da dupla.

O passado sempre teve uma posição privilegiada nas teorias psicanalíticas [...]. Mas o aclaramento obtido a partir da reconstrução do passado como explicação para o comportamento não é mais considerado um instrumento terapêutico tão mágico, como se imaginava no início da psicanálise. Ligaçóes com o passado são evidentemente importantes, contudo, não substituem o estudo das interaçóes vivas e das erosóes (Alvarez, 1994, p. 12).

Parece haver uma convergência entre diversos autores que a reconstrução do passado é, em geral, indireta, decorrente da função analítica de saber quem se é, conhecer o próprio olhar (e projeçóes) sobre o mundo. A compreensão do passado seria consequência desse conhecimento sobre o próprio mundo interno que, por meio da transferência, se torna presente na interação viva e atual com o analista:

Não é do passado que transferimos para o presente, mas de dentro para fora, do mundo interno para o mundo externo. [...] Estamos preocupados com a estrutura interna do paciente e como ela se apresenta em cada 
movimento. [...]. É o paciente que vai para o passado, tentando entender agora o que não entendeu lá atrás. Logo, o passado está no presente, não precisamos ir buscá-lo, basta que se exteriorize o que está dentro de nós (Andrade, 2009, p. 3).

Assim, podemos conhecer como o paciente transforma os acontecimentos, quer tenham sido eles passados ou estejam acontecendo no presente auxiliando, inclusive, o (re)conhecimento dos movimentos de transformação projetiva (Bion, 1965).

Esses aspectos são especialmente necessários naqueles casos em que um acontecimento traumático real é presente na história clínica. Nestes casos, o trauma real tende a ser utilizado de forma defensiva durante o processo analítico, servindo como álibi que explicaria de forma suficiente as perturbaçóes presentes (McDougall, 1983). Dessa forma, elementos conhecidos poderiam obstruir o caminho para o real objeto da psicanálise, limitando as possibilidades de transformação e questionamento.

Caper (2000) também considera que um mesmo fato passado poderia favorecer tantas suposiçóes sobre seus efeitos, que a reconstrução psicanalítica correria o risco de ficar baseada em especulaçóes sobre um acontecimento anterior. Para este autor, esse movimento teria um efeito antiterapêutico e saturado, uma vez que:

a ansiedade sobre "o que houve" no passado, geralmente, é um deslocamento da necessidade de saber o que está havendo [...]. A paixão por saber "o que houve" tende a evaporar assim que se pode saber o que está acontecendo (Caper, 2000, p. 129).

Puget (2008) amplia ainda mais esses questionamentos, apresentando consideraçóes sobre novos modos de pensar a temporalidade. Sob essa perspectiva, cada momento da relação analítica se configura como um presente recém-criado e fluido, contrastando com nossa tendência de organizar o tempo em termos conhecidos, consistentes e estáveis. Valoriza-se, assim, o tempo, a realidade psíquica e a maneira como o paciente se apresenta naquela relação e naquela sessão específica.

Nesse sentido, muito se tem questionado sobre a clássica tarefa de "transformar o inconsciente em consciente", conforme proposto por Freud, não apenas porque um acontecimento passado pode continuar a provocar danos (Alvarez, 1994), mas também porque o inconsciente deixa de ser entendido como elemen- 
to cristalizado e pronto, passando a ser visto como um inconsciente "móvel" e em permanente transformação (Ferro, 2010).

Aliás, esse movimento muitas vezes é acompanhado da necessidade de ajudar o paciente a "guardar" sua história, abrindo espaço para possibilidades novas. Alvarez (1994) observa que essa atenção ao presente torna o trabalho mais difícil, mas infinitamente mais vivo e interessante. Isso exige a confiança de que a relação nova e viva estabelecida pela dupla possa nutrir a mente de experiências emocionais potentes o suficiente para promover mudanças na qualidade psíquica da mesma.

Para exemplificar essa recomendação técnica, Alvarez (1996) apresenta, de forma corajosa e clara, um exercício de "revisão" do caso clínico de uma criança atendida por ela antes que as contribuiçóes teóricas de Bion estivessem disponíveis. A autora considera que, em muitos momentos, a experiência emocional foi substituída pelo uso saturado de um dado concreto e passado (a informação de que a mesma havia sido deixada pela mãe aos cuidados do pai e avó). Em uma das sessões, por exemplo, a criança diz: "Gosto das coisas que duram para sempre", e a autora reconhece:

$\mathrm{Eu}$ - lamento dizer - comecei a falar sobre sua mãe. Disse-lhe que sabia que sua mãe não morava mais com eles e perguntei se ele a tinha visto. [...] Eu tratei a insistência no "para sempre" como uma defesa contra a tristeza, ao invés de uma legítima necessidade de continuidade. [...] eu o estava empurrando de volta ao desespero [...]. Eu poderia ter dito: "Você gosta do sentimento de que este tratamento vai continuar por um longo tempo" (Alvarez, 1996, p. 41).

Assim, Alvarez (1994) chama nossa atenção para momentos do contato em que o trabalho transferencial corre o risco de ser substituído por uma "verdade histórica”, que impede a busca por reparação, continuidade e construção de uma nova realidade interna.

Assim, à medida que a psicanálise foi se aproximando dos estados mais primitivos da mente, novos percursos teóricos e técnicos foram necessários para abranger toda a complexidade do funcionamento psíquico, exigindo ampliação gradativa de espaço para o que não pertence ao campo do discurso (Mello Franco, 2006).

Tais considerações têm sido acompanhadas de progressiva aproximação da linguagem do inconsciente, em que o conteúdo do discurso passa a ocupar um lugar secundário frente à capacidade intuitiva do analista e seu instrumento de 
captação de emoções (Cassorla, 2009; Franco Filho, 2006; Ribeiro, 2010). Isso é especialmente importante quando se aborda aqueles elementos que náo alcançaram a qualidade de representação psíquica e permaneceram, portanto, como elementos sensoriais (Botella \& Botella, 2002, p. 29).

A diminuição da ênfase no conteúdo do discurso do paciente e a maior valorização dos aspectos não verbais presentes no campo da sessão e na dupla poderiam ser entendidas em dois "níveis" qualitativamente distintos:

1) aquele que opera com imagens e metáforas que, de alguma forma, ainda permanecem em termos de imagem-lembrança (sonho de vigília, memória sonho, capacidade de revêrie do analista, narraçóes construídas pela dupla, etc.); e

2) aquele que se refere ao sensorial, descrito por Botella e Botella (2002) como "mais além da representaçấo", e tende a operar pela via do fenômeno alucinatório.

A seguir, procuro considerar as contribuições teóricas referentes a esses dois níveis de trabalho e qualidade da mente.

\section{O campo, a dupla, a conversa, a narraçáo}

Ferro (1995) afirma que o conceito de campo (proposto pelo casal Baranger) permite um olhar mais amplo do que aquele sobre a relação, uma vez que o campo relacional e emocional faz referência a uma área intermediária, produto de duas vias mentais, com identificaçóes projetivas cruzadas entre analista e paciente e com produçôes oníricas do par.

É nessa área intermediária que a psicanálise passa a operar, com elementos compartilhados que poderiam ser descritos em um ciclo de transformaçóes. Assim, cada aquisição de conhecimento $(+\mathrm{K})$ abre espaço para o desenvolvimento de um novo pensamento e o trabalho passa a ganhar profundidade.

Ainda nessa área intermediária da dupla, Ferro (1995) descreve aspectos "par-específicos", ou seja, aqueles espontaneamente produzidos em resposta ao movimento daquela relação. Um exemplo dessa possibilidade técnica podem ser personagens que são criados na sessão, por intermédio de diálogos, desenhos, jogos ou sonhos e passam a ser referências na história daquela dupla. Qualquer um desses elementos pode ser entendido como algo que espera por um desenvolvimento narrativo. 
Isso indica que a narração ainda será desenvolvida, criada. É contrária à ideia de uma produção que já tem significado pronto, a ser desvendado ou escavado pelo terapeuta para ser entregue ou revelado ao paciente. Na verdade, cada um desses personagens vai ganhando vida e forma ao longo das sessóes e admite possibilidades dinâmicas de transformação, da mesma forma como a relação.

Assim, embora já tão difundida a ideia de Winnicott de que a ação de brincar, mais do que o conteúdo da brincadeira, teria efeito psicoterápico e criativo (Fulgencio, 2008), ainda não é incomum entre terapeutas de crianças o incômodo e a angústia frente às sessóes que se repetem, às muitas brincadeiras "sem significado", ou que "não estão sendo interpretadas" do ponto de vista da técnica clássica.

Considerando nosso interesse nas construçōes em análise, cada uma dessas contribuiçóes poderia ser entendida como uma unidade de construção (um tijolo), sendo comum, inclusive, que várias sessôes sejam necessárias para que algo possa tomar forma e construir um sentido de elaboração.

Essa ideia de que a interpretação possa ser resultado de uma construção prévia tem sido discutida e revisada, conforme abordado por Canelas Neto (2008), que comenta sobre um congresso ocorrido em Genebra, exatamente com o tema "construçôes em análise". Refere que o debate interpretação versus construção possibilitou questionamentos importantes, desde aqueles que consideraram que a construção viria no lugar da interpretação, provindo de uma impossibilidade de interpretar, até a ideia que alicerça este trabalho de que a interpretação é função de uma construção prévia e implícita.

Essa maneira de se aproximar do material da sessão até que um sentido possa ser construído é válida tanto para o atendimento de crianças como de adultos:

É possível que tenhamos que permanecer com a criança por um longo tempo, completamente no escuro sobre o que está se passando, até que, de repente, alguma coisa surja [...] e entáo interpretamos, às vezes, sem sermos capazes de ver como chegamos àquela conclusão (Bick, 1990, p. 190).

Da mesma forma, Assis (2009) destaca o papel fundamental da conversa para ir abrindo espaço de aproximação da experiência emocional até que este movimento possa contribuir para o fortalecimento do aparelho mental. Sob essa perspectiva, a conversa com o adulto, vista como fala não interpretativa, ao mesmo tempo que delimita o campo, também amplia investigaçóes, semelhante ao brincar da ludoterapia. 
Assim, crianças podem brincar, desenhar, contar histórias; adolescentes descrevem filmes, trazem músicas em seus celulares ou aparelhos eletrônicos. Adultos referem-se aos acontecimentos cotidianos e às relaçóes estabelecidas. Tudo pode ser acolhido como brechas do mundo interno que permitem promover histórias, constituindo elementos para a construção de uma representaçáo.

Ferro (1995) nos convoca a perceber que os elementos do mundo interno do paciente nos serão apresentados de forma muito variada, tanto no atendimento de crianças, como de adultos. Esse autor sugere, de forma criativa, que o conteúdo do discurso de um paciente adulto poderia, por exemplo, ser descrito como um sonho, um filme ou ter sido expresso por um desenho.

Nesse sentido, uma das funçóes terapêuticas propiciadas pelo diálogo na sessão é criar condições de um movimento centrípeto, ou seja, do conteúdo do discurso aos aspectos do mundo interno. Muitas vezes esse trabalho de condução do paciente ao interno é a tarefa do terapeuta com uso de palavras que sirvam como senhas, ao fazer referência ao que é pleno de significado para o paciente.

Assim, a brincadeira (jogo, desenho ou mesmo o diálogo do adulto) permite que nos aproximemos daquilo que é sentido como mais ameaçador pelo paciente. Aliás, não é incomum que níveis de deformação ou desorganização, sejam, gradativamente, apresentados na sessão.

O mais interessante é que, inicialmente, esse novo desafio técnico foi decorrente da experiência clínica com pacientes bastante comprometidos e os chamados casos limite, que submetem o psiquismo do analista a um trabalho árduo:

[...] nos casos difíceis, o analista deve, ele mesmo, fazer um esforço considerável de representaçáo daquilo que o paciente náo pode representar, isto é, o analista deve fazer como se colocasse seu próprio aparelho mental em ação, como auxiliar do aparelho mental do paciente (Green, 1990, p. 65).

Contudo, quanto mais reconhecemos que as oscilaçóes nos estados de mente são próprias ao funcionamento psíquico de todos nós (Bion, 1957/1991; Meltzer, 1986/2004; Ogden, 1996), mais somos solicitados a lidar com aspectos primitivos da vida mental constantemente atuantes.

Nem sempre estamos disponíveis para essa aproximação, que requer muita disposição psíquica. Não é incomum recorrermos a manobras para aliviar, valorizar, empatar ou proteger os pacientes, especialmente quando se criam zonas de resistência do par (Ferro, 1995) que impedem ou interferem no eclodir da própria violência. 
Muitas vezes, por exemplo, estados de angústia descritos nos sonhos parecem transbordar na vigília, exigindo um trabalho de busca por representação que permita processar esses elementos e deixá-los como sonho. A representação teria a função de transformar o que era infinito e sem nome em algo finito e mais conhecido.

Nesse sentido, Assis (2009) retoma a questão da representação a partir da teoria do trauma. Sob esta perspectiva, a representação seria equivalente a um processo de cicatrização.

Assim, para ser eficaz e permitir representação, a nomeação exige um ritmo próprio, que permita abordar os conteúdos que necessitam de simbolização. Nesse sentido, uma nomeação exerceria a função de conter elementos anteriormente dispersos (Assis, 2009).

Existe, assim, um desafio técnico para lidar com um limite tênue dos efeitos de uma nomeação. Se, por um lado, nomear pode favorecer contenção, por outro pode exercer apenas uma função defensiva e de evasão, que não favorece o desenvolvimento do pensamento. Especialmente quando é feita apressadamente, a nomeação pode simplesmente ser ineficaz ou ainda interromper um caminho de investigação: "definir é aprisionar algo dentro de certos limites; a verbalização não libera seu significado, mas nega-lhe uma saída” (Bion, 1963/2004, p. 40).

Esse risco entre o uso "sofisticado" da linguagem para expressar abstração ou falsear/impedir o desenvolvimento do pensamento foi também abordado na introdução feita pela sociedade de psicologia do Rio Grande do Sul na apresentação do livro de Botella e Botella (2002, p. 14):

O analista que se apressa a "colocar palavras" provavelmente o faz em um movimento defensivo ante o temor à perda das suas próprias representaçôes frente ao contato com o irrepresentável do paciente. [...] o analista tem que "perder as palavras" afastando-se das categorias têmporo-espaciais do pré-consciente, entregando-se a uma espécie de estado onírico favorecido pela atenção flutuante.

Assim, o trabalho analítico poderia ser descrito como uma oscilação permanente entre o concreto e o abstrato; nesse modelo, a noção de interpretaçáo é ampliada para uma função interpretativa (Guignard, citado por Lewkowics \& Lewkowics, 2011) ou ação interpretativa (Ogden, citado por Lewkowics \& Lewkowics, 2011). A atividade interpretativa passa, então, a abranger tudo o que ajuda o paciente a saber mais de seu funcionamento e conhecer melhor o que está sendo vivido. $\mathrm{O}$ trabalho passa a ser, portanto, o de transformar a experiência emocional em conhecimento. 
Assim, até esse momento abordamos intervençóes importantes tentando encontrar possibilidades para construir representaçóes de estados psíquicos. Contudo, a partir daqui inicia-se uma "impossibilidade" - usar palavras para escrever sobre a ausência delas. Aliás, a ideia de "perder as palavras" em uma atividade cuja base é verbal (talking cure) é bastante desafiadora. É como se perdêssemos as diretrizes técnicas do que consideramos até esse momento.

Fomos das imagens às palavras. Vamos entấo ao caminho inverso, à perda de nossa própria representaçẫo. Agora precisamos "voltar" e abdicar da lógica convencional que habitualmente nos norteia.

\section{Perdendo as palavras - a via "regrediente"}

Como visto, a construção de representação pressupôe uma condição prévia de simbolizaçáo, recurso sofisticado e nem sempre acessível, especialmente quando se transita com níveis mais primitivos de estados mentais, em que não é possível uma delimitação clara entre processos inconscientes e conscientes.

Vale destacar que estamos abordando questóes muito presentes na psicanálise contemporânea. Contudo, é intrigante observar como Freud já destacava a força das "alucinaçóes não psicóticas", que poderiam fazer referência a experiências sensoriais, que deixaram um registro primitivo e não verbal:

Essas recordaçóes poderiam ser descritas como alucinaçôes. [...] ocorriam ocasionalmente no caso de pacientes que certamente não eram psicóticos. [...]. Talvez seja uma característica das alucinaçôes [...] que algo que a criança viu ou ouviu numa época que mal podia falar e que agora força o seu caminho à consciência (Freud, 1937/1980, p. 301).

Nesses casos, inicia-se um caminho em uma direção anterior à representação-imagem, conforme abordado no trabalho de César e Sara Botella (2002). O que se propóe é retornar ao inconsciente, "regredir" às sensaçóes, à procura de flashes de imagens que promoveriam a possibilidade de nascimento de um esboço (precursor) do mundo de representaçóes.

De acordo com McDougall (1983), experiências sentidas como catastróficas não deixariam recordaçôes traduzidas em pensamentos ou comunicaçóes e, por isso mesmo, não poderiam ser expressas pelos mesmos recursos de abstração e pensamento considerados anteriormente. Os registros dessas experiências, contudo, permaneceriam como sinais inscritos no soma, que seriam acessíveis "pelas 
incoerências e brancos que provocam no registro do pensamento" (McDougall, 1983, p. 101).

Assim, para manter o modelo de construção que usamos até aqui, é como se estivéssemos agora frente aos "destroços" do psiquismo, termo bastante apropriado utilizado por McDougall (1983) para abordar os aspectos primitivos da comunicação analítica.

Em geral, existe uma convergência entre os autores de que os caminhos pelos quais os "destroços" atingem o analista passam pelo somático e/ou pela interferência na integridade de seu funcionamento lógico habitual. Isso se daria pela chamada regressão formal do pensamento ou trabalho por via regrediente (Botella \& Botella, 2002) do analista, uma desconstrução da palavra, ampliando a importância da capacidade intuitiva e até mesmo da cadência rítmica das palavras do analista:

$\mathrm{Na}$ via da regressão formal do pensamento, no analista em sessão, o alucinatório pode às vezes, se desenvolver em estados psíquicos particulares, - "acidentes de pensamento [...] permitindo ao analista a intuição e a compreensão da não representação do paciente" (Botella \& Botella, 2002, p. 107).

Botella e Botella (2002) descrevem, por exemplo, um caso clínico em que a analista e a paciente, uma criança de cinco anos, estavam envolvidas, já por algumas sessóes, na análise de um sonho descrito pela criança. Subitamente, contudo, a analista esqueceu completamente o nome da criança. Esse esquecimento é seguido de estranheza, mas logo substituído pela lembrança (uma imagem auditiva) que se impóe no curso do pensamento. Os autores fazem uma distinção entre o fenômeno da contratransferência e a figurabilidade que, segundo eles, seria mais apropriada para esse caso, ao descrever uma "ruptura" de memória como esta.

Esses "lapsos" no funcionamento lógico também foram abordados por Ogden (1996), em sua conceituação da posição autística-contígua. Esse autor apresenta, de forma enfática, o risco de aprisionamento em um mundo de sensaçóes, carentes de símbolos. Ogden refere uma experiência pessoal em que vivenciou a perturbadora experiência de desconexão entre o sensorial e a palavra (símbolo):

Depois do jantar, uma noite, enquanto ainda sentado na mesa de jantar, de repente ocorreu-me como era estranho que uma coisa chamada "napkin" (guardanapo) era designado pela elisão dos sons nap e kin. Eu repeti os dois sons de novo e de novo até que comecei a ter a sensação assustadora de que 
esses sons não tinham conexáo alguma com a coisa que eu estava olhando. Eu não conseguia fazer com que esses sons naturalmente "significassem" a coisa que eles significavam dois minutos antes. $\mathrm{O}$ vínculo estava desfeito e, para meu horror, não poderia ser restabelecido por um ato de vontade. [...] tive um sentimento muito perturbador de haver descoberto uma maneira de enlouquecer (Ogden, 1996, p. 361).

As marcas desses estados mentais poderiam ser descritas por desconexóes de elos, rompimentos de vínculos importantes que mantêm a integridade do funcionamento lógico e sua associação com o estado emocional e psíquico. Nesse sentido, as ansiedades primitivas são expressas, por exemplo, pelo temor de desintegração, esvaziamento de conteúdos corporais ou perda do contorno corporal (Ogden, 1996; Meltzer, 1975/1986).

Existe, assim, uma convergência entre os autores de associação entre o estado mental primitivo e o registro somático. A comunicação desses estados mentais também seria feita, portanto, através de processos de Identificação Projetiva, uma vez que carecem de simbolização e abstração.

Dessa forma, o analista também sofreria ação desses elementos através do corpo, conforme descrito por Green (1990):

[...] diante de certas situações irrepresentáveis, a excitação vai encaminhar-se ao somático e exprimir-se, mesmo durante a sessão, através do somático [...]. Essas manifestaçóes do corpo, em análise, são muito mais importantes do que se imagina. Essas manifestações estão ligadas ao afeto e à reconversão somática do afeto (Green, 1990, p. 66).

A comunicação de eventos psíquicos através de violentas identificações projetivas permitiu retomar a interface trabalho psicanalítico, intuição e premonições decorrentes da intersubjetividade da mente. Esses movimentos de sinalização teriam função antecipatória de captação de emoçóes nascentes (Ribeiro, 2010).

Nessa mesma linha, partindo das considerações de Freud acerca de processos de "transmissão de pensamento" (1933/1980), Pontes e Torrano (2010) ampliam o estudo das comunicaçóes inconscientes, relatando que as mesmas podem não ser restritas ao setting formal, pois também ocorrerem fora da sessão de análise (embora ainda dentro do campo analítico, de comunicação inconsciente). Assim, por força da relação transferencial, as comunicações seriam sentidas como premoniçóes, comparando esse fenômeno ao modelo de tecnologia Bluetooth de 
comunicação sem fio e apresentando casos clínicos em que a analista teve flashes e sentimentos antecipatórios de eventos importantes vividos por algumas de suas pacientes.

Não resta dúvida de que as modificações técnicas favoreceram modalidades de escuta mais abrangentes, incluindo o não pensado e o não dito (Lewkowics \& Lewkowics, 2011) e permitindo diversificar os meios de produção de subjetividade e de acesso ao inconsciente.

Contudo, é fundamental verificar de que maneira esses novos elementos serão inseridos no trabalho analítico. Para se desvincular de seu caráter "mágico", esse novo modelo exige do analista uma qualidade de mente capaz de "transformar o intuído em formulação" (Ribeiro, 2010, p. 146), tarefa essencial que permite ao paciente a aquisição de conhecimento $(+K)$ e a elaboração psíquica.

Deparamos-nos, portanto, com dois desafios na prática clínica: o trabalho intuitivo com o negativo, não representado e não simbolizado, portanto não falado; e a mudança de vértice no objetivo da psicanálise que passa a priorizar o movimento dianteiro e, por vezes, antecipatório, de conhecer "onde estamos e para onde vamos" (Sapienza, 2012).

A integração dessas consideraçóes chama a atenção para a prática psicanalítica contemporânea, que busca percorrer um caminho mais prospectivo do que retrospectivo na (re)construção permanente do inconsciente.

\section{Referências}

Alvarez, A. (1994). Companhia viva-psicoterapia psicanalitica com crianças autistas, borderline, carentes e maltratadas. Porto Alegre: Artes Médicas.

Alvarez, A. (1996). Identificação Projetiva como comunicação: sua gramática em crianças psicóticas borderline. Revista Brasileira de Psicanálise, 30(1), 35-46.

Andrade, S. H. (2009). Transferência e contratransferência. Trabalho original apresentado na Sociedade de Psicanálise de Campo Grande. Recuperado em 2 de fevereiro, 2012, de $<$ http://www.cursosuad.com.br/tranferencia-e-contratransferencia>.

Assis, M. B. A. C. (2009). Conversa na sessão de análise. XXII Congresso Brasileiro de Psicanálise, Rio de Janeiro, Brasil.

Bick, E. (1990). Análise de crianças hoje. In M. Feldman \& E. B. Spillus (Eds.), Coleção nova biblioteca de psicanálise - Melanie Klein hoje, v. 2 (pp. 186-195). Rio de Janeiro: Imago.

Bion, W. R. (1991). Aprender com a experiência. Rio de Janeiro, Imago. (Trabalho original publicado em 1957) 
Bion, W. R. (2004). Elementos de psicanálise. Rio de janeiro: Imago. (Trabalho original publicado em 1963)

Bion, W. R. (1965). Transformaçôes. Rio de Janeiro: Imago.

Botella, C., \& Botella, S. (2002). O irrepresentável: mais além da representação. Porto Alegre: Sociedade de Psicologia do Rio Grande do Sul/Criação Humana.

Canelas Neto, J. M. (2008). Construções em análise: alguns elementos relevantes de discussão no $68^{\circ}$ Congresso de Psicanalistas de Língua Francesa. Revista Brasileira de Psicanálise, 42(3), 83-90.

Caper, R. (2000). Psicopatologia e estados mentais primitivos. In Livro Anual de Psicanálise, XIV, 121-132. São Paulo: Escuta.

Cassorla, R. (2009). Reflexôes sobre não-sonho-a-dois, enactment e função-alfa implícita do analista. Revista Brasileira de Psicanálise, 43(4), 91-120.

Falcão, L. (2008). Construções em análise hoje: a concepção freudiana ainda é válida? Revista Brasileira de Psicanálise, 42(3), 69-82.

Ferro, A. (1995). A técnica na psicanálise infantil: a criança e o analista: da relação ao campo emocional. Rio de Janeiro: Imago.

Ferro, A. (2010). Quem o viu? O espectro do onírico. Bergasse 19, 1(1), 15-33.

Franco Filho, O. M. (2006). A experiência dos místicos e do psicanalista sob o vértice de Bion. Revista Brasileira de Psicanálise, 40(3), 33-47.

Freud, S. (1980). Conferência XXX - Sonhos e ocultismo. In S. Freud, Edição standard brasileira das obras psicológicas completas de Sigmund Freud, v. XXII. Rio de Janeiro: Imago. (Trabalho original publicado em 1933)

Freud, S. (1980). Construções em análise. In S. Freud, Edição standard brasileira das obras psicológicas completas de Sigmund Freud, v. XXIII. Rio de Janeiro: Imago. (Trabalho original publicado em 1937)

Fulgencio, L. (2008). O brincar como modelo de método de tratamento psicanalítico. Revista Brasileira de Psicanálise, 42(1), 124-136.

Green, A. (1990). Conferências brasileiras. Rio de Janeiro: Imago.

Lewkowics, S., \& Lewkowics, A. (2011). Função interpretativa: dois personagens em busca de sentido. Revista Brasileira de Psicanálise, 45(3), 51-60.

McDougall, J. (1983). Contratransferência e comunicação primitiva. In J. McDougall, Em defesa de uma certa anormalidade (pp. 98-114). Porto Alegre: Artes Médicas.

Meltzer, D. (1986). Identificação adesiva. Jornal de Psicanálise, 19(38), 40-52. (Trabalho original publicado em 1975)

Mello Franco, O. (2006). A experiência dos místicos e a do psicanalista sob o vértice de Bion. Revista Brasileira de Psicanálise, 40(3), 33-47.

Ogden, T. H. (1996). Sobre o conceito de uma posição autística-contígua. Revista Brasileira de Psicanálise, 30(2), 341-364. 
Pontes, A. R. N., \& Torrano, L. M. (2010). Espaço vivo: a comunicação inconsciente interpsíquica (paciente/analista) segundo o modelo Bluetooth na psicanálise. Bergasse 19, 1(1), $37-49$.

Puget, J. (2008). O uso do passado e do presente no setting psicanalítico - passados e presentes. In Livro Anual de Psicanálise, XXII, 253-265. São Paulo: Escuta.

Ribeiro, M. M. M. (2010). Premonições na experiência analítica: intuição e teorias de observação. Bergasse 19, 1(1), 136-153.

Sapienza, A. (2012). A clínica psicanalítica. Aula Inaugural do Instituto de Psicanálise da Sociedade Brasileira de Psicanálise de Ribeirão Preto, São Paulo, Brasil.

Recebido em 05 de março de 2012 Aceito para publicação em 31 de março de 2012 